\title{
Modelling the persistence of mosquito vectors of malaria in Burkina Faso
}

\author{
Ace R. North ${ }^{*}$ and H. Charles J. Godfray
}

\begin{abstract}
Background: Populations of the Anopheles gambiae complex are found during the rainy season throughout West Africa, even in arid areas with long dry seasons during which mosquitoes appear to be absent. Several hypotheses have been proposed to explain this apparent paradox, including aestivation, dispersal between neighbouring settlements, and long distance migration using high-altitude wind currents.

Methods: An individual-based, spatially explicit model of mosquito populations was developed for a region of West Africa centred on, and including all of, Burkina Faso. Populations associated with human settlements were linked by dispersal and the model incorporated geospatial data on the distribution of settlements, water bodies and rainfall.

Results: Local dispersal (at rates consistent with experimental data) was necessary to explain observed patterns of rainy season populations across all of the simulation area, but by itself failed to account for the presence of populations in the arid North (the Sahel). The presence of rare dry-season larval sites could explain these northern populations, but seems inconsistent with field surveys. Aestivation by female mosquitoes explained rainy-season populations in all but the very sparsest and driest areas of human habitation, while long-distance migration based on annual wind patterns could account for all observed populations.

Conclusions: Modelling studies such as this can help assess the potential validity of different hypotheses and suggest priority areas for experimental study. In particular, the results highlight a shortage of empirical research on mosquito dispersal between neighbouring settlements, which may be critically important to the continued presence of many mosquito populations in West Africa. Further research that establishes the extent to which mosquitoes aestivate, and migrate using high altitude winds, is also much needed to understand Sahelian mosquito populations.
\end{abstract}

Keywords: Anopheles gambiae, Anopheles coluzzii, Mosquito aestivation, Mosquito migration, Model

\section{Background}

Despite enormous progress in recent years, malaria remains hyper-endemic in large parts of sub-Saharan Africa [1]. The most severely afflicted region is West Africa which contains eight of the ten countries that had the highest incidence in 2015 (Mali, Burkina Faso, Guinea, Côte d'Ivoire, Togo, Nigeria, Sierra Leone, and Benin; [1]). To understand why malaria is so persistent here and to refine control methods, it is critical to understand the population biology of malaria vectors in the region.

\footnotetext{
*Correspondence: ace.north@zoo.ox.ac.uk

Department of Zoology, University of Oxford, Woodstock Road,

Oxford OX2 6GG, UK
}

The four major mosquito vectors of malaria in AfricaAnopheles gambiae sensu stricto (s.s.), Anopheles coluzzii, Anopheles arabiensis, and Anopheles funestusare all present in sub-Saharan West Africa [2], and all undergo population dynamics driven by a highly seasonal cycle of rainfall (until molecular diagnostics were developed the first three species were lumped in the taxon Anopheles gambiae sensu lato (s.l.), but the narrow concept of the species is used below). There is a rainy season, typically between July and November, with the rest of the year being hot and dry. The duration and amount of rain during the rainy season varies markedly along a North-South axis (the northernmost part, the West African Sahel, being the driest) and also from year to year in any given location [3]. Mosquito populations increase 
dramatically each rainy season due to the creation of larval sites in puddles and along the edge of temporary streams, and then decline when these sites dry up as the rainy season ends. The precise timing of population growth and decline differs amongst vector species [4-8], for reasons that are not fully resolved though a key factor is thought to be how each species survives the dry season [8]. In much of the region, mosquito populations seem to disappear completely in the dry season only to reappear at the onset of the rainy season $[4,5,8,9]$, even in very arid regions. How mosquito populations are maintained during the dry period remains unclear, despite decades of research, though there are three main hypotheses [4].

First, it has long been known that that some adult mosquitoes hide in (largely unknown) shelters during the dry season in a semi-dormant state (aestivation; $[9,10]$ ). There is mounting evidence that this behaviour plays a role in the persistence of some An. coluzzii populations $[8,11-15]$, though there remains less evidence that other anophelines aestivate [8]. Second, localities might be colonised at the start of the rainy season by mosquitoes dispersing from nearby locations where there are persistent populations owing to year-round surface water. Although there is good evidence that this occurs in some locations $([4,16]$ (West Africa); $[17,18]$ (East Africa)), it seems an unlikely explanation for vector persistence in parts of the Sahel which are remote from permanent water (for example at least $30 \mathrm{~km} ;[13,14])$. The third possibility is that mosquitoes migrate long distances by passive transport in high-altitude winds to recolonise habitats each rainy season. This hypothesis dates back to the 1960s [19], yet it has received less attention in recent decades which may reflect the difficulty of obtaining evidence of mosquitoes travelling large distances. However, interest has revived following the publication of trap data from a Sahelian village in Mali, where An. gambiae were undetected in the dry season yet abundant in the latter part of the rainy season [8]. The nearest large (and year-round) populations of An. gambiae are at least $\sim 150 \mathrm{~km}$ from this study site, hence migration spanning hundreds of kilometres appears necessary to explain the observed dynamics [8].

It is of course possible that these processes combine to allow vector persistence throughout the region, in a manner that depends on location as well as species. In the case of An. coluzzii, recent genetic data from a Malian Sahel village (the same study site as [8]) has suggested that this population survives the dry season predominantly by aestivation (in agreement with [8]), yet long distance migrants also arrive over the course of a rainy season [15]. However, two studies comparing populations of An. coluzzii from locations close to or more distant (at least $30 \mathrm{~km}$ ) from permanent surface water, found traits indicative of aestivation only in the remote populations (reduced oviposition despite having access to water [13]; reduced flight activity [14]).

This paper develops a simulation model of the dynamics of a mosquito species to explore vector persistence in Burkina Faso and the surrounding region. The model is intended to represent either An. gambiae or An. coluzzii, which are probably the most efficient malaria vectors in the world $[20,21]$. The distributions of these sibling species differ in West Africa, though they are sympatric in much of the study area $[2,22]$. Although the two species have somewhat different ecologies [22-25], the model is used to investigate entomological parameters that are uncertain for both species, in particular those relating to dry season ecology and movement behaviour.

The model is individual-based [26] and assumes that the structure of the mosquito metapopulation in the study region can be represented by the ensemble of connected populations associated with individual human settlements. This assumption is made because An. gambiae and An. coluzzii are well known to be highly anthropogenic $[21,27-30]$. The individual-based nature of the current model allows stochasticity to be considered in a natural manner, which means that population sites may become extinct when conditions are unfavourable and later recolonised if conditions become favourable. The model incorporates geospatial data on human settlements, water courses (rivers and lakes), and rainfall.

Several other large-scale models of mosquito dynamics in Africa have been developed that adopt different assumptions about mosquito population dynamics. For example the Liverpool malaria model (LMM) [31-33] and the Open Malaria Warning (OMaWa) model [34, 35] are deterministic which improves computational efficiency though makes it harder to represent stochasticity. A number of stochastic and spatially explicit models have been described [36-38], though these were intended for the investigation of anopheline dynamics across small areas (village-sized [36, 37]) or medium areas (region-sized, $\sim 1000 \mathrm{~km}^{2}$ [38]), and their simulation on a country-sized area would be computationally prohibitive. The large and medium scale models all represent African mosquito metapopulations as the ensemble of populations at the points of a lattice. This again is computationally efficient though makes it harder to incorporate the geographical heterogeneity that may affect population persistence, and also makes it more difficult to compare model results with field surveys that are typically based at human settlements. The approach used here would be less suitable to mosquito species with low rates of anthropophily, or which breed in areas with sparse human habitation, where a lattice formulation may be preferable. Compared to LMM and OMaWa, a relatively simple model for mosquito dynamics is used, 
that assumes population growth rates are not influenced by temperature and humidity. This is done in order to focus on the role of variation in rainfall and groundwater (and for computational efficiency) and this assumption is returned to in the discussion.

The aim of this work was to explore how assumptions about mosquito behaviour affect population persistence across an area of West Africa that is large enough to exhibit the wide variation in environmental conditions found in this region. In particular, the model is used to address the observation that mosquito populations occur during the rainy season in the driest locations in the study area. The results suggest that population persistence in these areas requires either aestivation, long-distance movements or the presence of year-round breeding sites, and the different effects these processes have on mosquito population dynamics are explored.

\section{Methods}

An individual-based model was developed to simulate mosquito populations in an area of West Africa centred on, and including, Burkina Faso. The model takes account of spatial variation in rainfall patterns, the presence of rivers and lakes, and the distribution of humans. The mosquito population across the entire simulation area is treated as a network of local populations located at human settlements, and it is assumed that local populations are connected to neighbouring populations through the short-distance dispersal of adult mosquitoes. For some simulations, it is assumed in addition that more distant populations are connected by the long distance migration of adult females. The maximum density of a local population is assumed to be influenced by both the amount of rainfall at a given time, and the presence and extent of local water bodies (which may be seasonal or permanent).

\section{Simulation region}

The model is set it a region of West Africa with sides of $10^{3} \mathrm{~km}$ centred on the mid-point of Burkina Faso (longitude $-1.737^{\circ}$, latitude $\left.12.274^{\circ}\right)$. This region includes all of Burkina Faso and territory of seven neighbouring countries (Mali, Niger, Nigeria, Benin, Togo, Ghana, and Côte d'Ivoire; Fig. 1). A recent review [2] collated studies that recorded the presence of malaria vector species in different locations across Africa, and this included 330 records of An. coluzzii and 321 records of An. gambiae in 150 sites within the study region (Fig. 1).

\section{Distribution of human settlements}

The model uses settlement data collected by the United Nations Office for the Coordination of Humanitarian Affairs (OCHA), which is available from the
Humanitarian Data Exchange (HDX; https://data.humda ta.org/). These data give the location, name, region and country of villages, towns, and cities throughout the region (larger towns and cities may also be subdivided into smaller settlement units), comprising 42,360 human settlements in total (Fig. 1).

\section{Distribution of water bodies}

Inland water data extracted from the digital chart of the world $(\mathrm{DCW})$, which includes all significant water courses in the region (available from http://www.diva-gis. org/Data), is used to set the distribution of water bodies. Rivers and other water bodies are represented as a series of segments (lines or polygons), each of which is classified as either "non-perennial, intermittent, or fluctuating" or "perennial or permanent". The edges of the polygon segments (representing lakes and wide rivers) were extracted from these data, and treated as linear habitat elements since An gambiae s.l. tends to breed at the periphery of large water bodies [25]. In total, these data comprise $63,299 \mathrm{~km}$ and $61,953 \mathrm{~km}$ of non-perennial and perennial water courses within the simulation region (Fig. 1).

\section{Rainfall}

Rainfall data were obtained from the "ERA-interim reanalysis", covering the period January 1st 1979 to February 28th 2017 at a spatial resolution of 0.5 degrees (longitude and latitude), which is available from the European Centre for Medium-Range Weather Forecasts [39]. The data were aggregated to obtain weekly total rainfall for each grid square. There is considerable variation in the amount of rain falling across the simulation region, though most parts experience a rainy season between August and September and are driest between December and April (see Additional file 1).

\section{Mosquito demographic model}

Each human settlement is assumed to represent the potential site of a mosquito population which is made up of juveniles, adult males, virgin females, and mated females. The juvenile category includes all immature mosquito stages from egg to pre-reproductive adult, which is assumed to last for $T_{L}$ days (treated as a constant). The simulation model keeps track of the numbers of individuals in each life-stage, which are updated each day using pseudo-random draws from appropriate probability distributions.

Each day, juveniles either die or age by 1 day. The probability that a juvenile survives is $p_{s}=\sqrt[T]{t} \frac{\alpha(x, t)}{\alpha(x, t)+J_{T}}\left(1-\mu_{J}\right)$ where $\mu_{J}$ represents density independent mortality, $J_{T}$ is the total number of juveniles in the population, and $\alpha(x, t)$ is a variable controlling the strength of mortality 


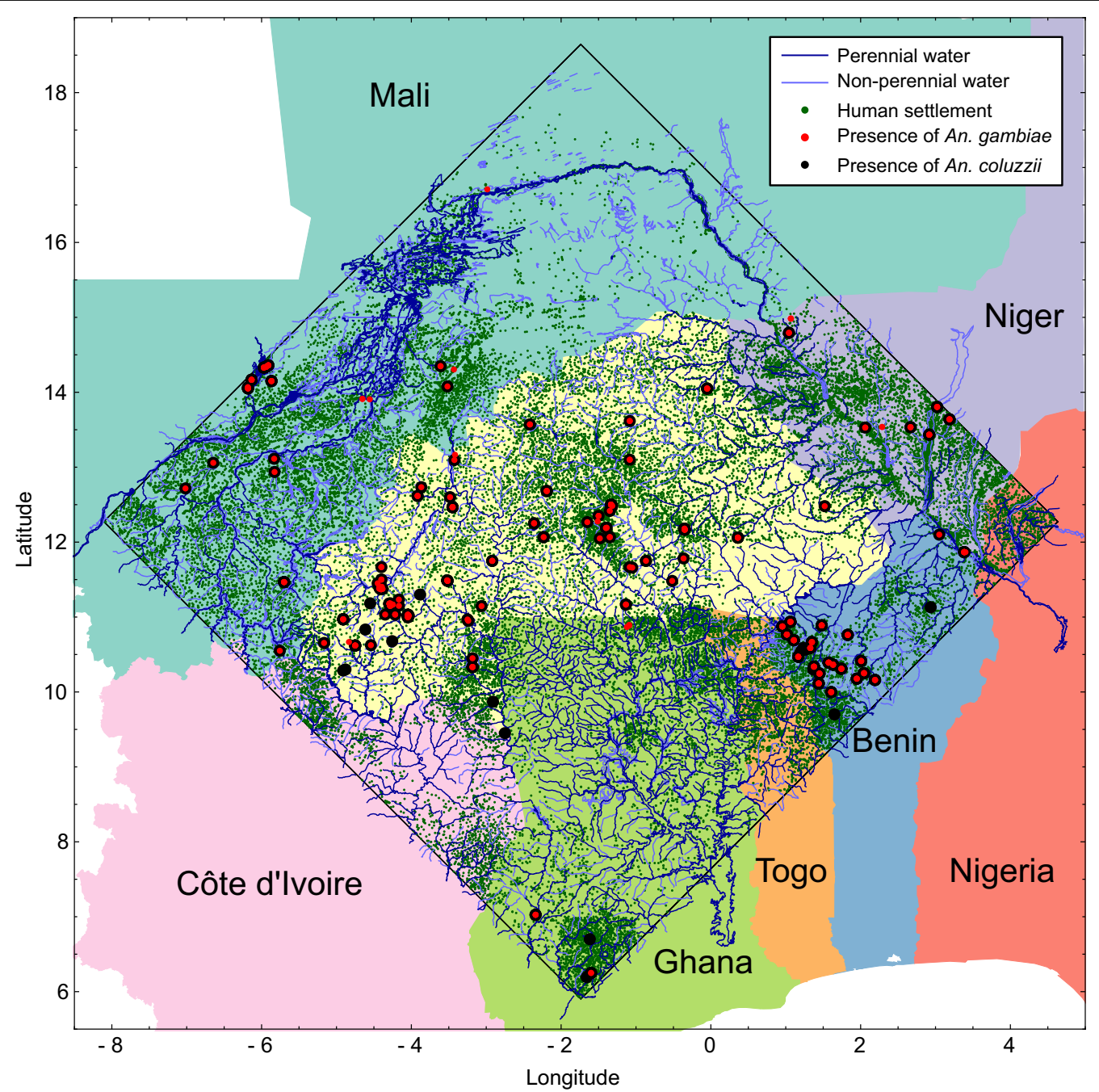

Fig. 1 The simulation area, delineated by the square whose sides are $1000 \mathrm{~km}^{2}$. Note that the black and red presence markers show all the locations where entomological studies have been performed (there are no absence markers; [2])

due to larval competition for resources $(\alpha(x, t)$ is the number of juveniles at which the probability of death from larval competition over the course of development is 0.5$)$. This quantity varies over space $(x)$ and time $(t)$ because it is influenced by rainfall and the presence of local water bodies (see below).

Adults die with probability $\mu_{A}$ per day and over the same period virgin females mate with probability $p_{m}=\frac{M}{\beta+M}$, where $M$ is the number of males in the population and $\beta$ is the adult male population size at which the daily probability of mating is 0.5 . This parameter is set at the low value of 100 , so that females almost always mate on their first day after emergence in all but very small populations. This is on the assumption that there are very few old virgin females in anopheline populations.
Unfortunately, no data was found that would allow this parameter to be estimated more accurately.

Each day a mated female lays a number of eggs, which is Poisson distributed with expectation $\theta$. All juveniles when they reach age $T_{L}$ emerge to become an adult male or virgin female with equal probability.

Adults disperse locally with probability $d$ to sites within a neighbourhood of radius of $L_{D}$. Within this area, the probability of moving from focal site $i$ to site $j$ (from within the $k$ sites in the neighbourhood) depends on their distance apart, $d_{i j}$, and is $\frac{L_{D}-d_{i j}}{\sum_{k}\left(L_{D}-d_{i k}\right)}$. Note that the distribution of distances for local dispersal events depends on the location of the focal settlement-dispersal from settlements with many neighbours is typically more short-range than dispersal from isolated settlements. This contrasts with 'lattice' spatial models, 
where populations are typically equidistant (e.g. [34, 38]). An additional figure plots the variation in the mean distance of a dispersal event across all settlements in the simulation area (see Additional file 2).

\section{Influence of water courses and rainwater}

The presence of local water bodies influences larval competition and thus carrying capacity. It is assumed that a population at location $x$ at time $t$ has a value of the function, $\alpha(x, t)$ that determines local maximum density,

$$
\begin{aligned}
\alpha(x, t)= & \alpha_{0}(x)+\alpha_{1}\left(1-e^{-\phi r(x, t)}\right) \\
& +\alpha_{2}\left(1-e^{-\kappa\left[W_{p}(x)+W_{n}(x)\left(1-e^{-\delta r(x, t)}\right)\right]}\right) .
\end{aligned}
$$

The first term, $\alpha_{0}(x)$, is assumed absent in the baseline version of the model and is returned to below.

The second term represents the contribution to breeding habitats from rainfall $r(x, t)$ through, for example, the creation of puddles and other small water bodies in which An. gambiae s.l. is known to breed. In the absence of rainfall this term is zero, but as precipitation rises it increases at a rate determined by the parameter $\phi$ to asymptote at a level $\alpha_{1}$. Recall that rainfall is averaged by week so that, at any given location $x, \alpha(x, t)$ varies on a weekly rather than daily basis.

The final term represents the larval sites associated with rivers and lakes which may be permanent, $W_{p}(x)$, or intermittent, $W_{n}(x)$. The magnitude of the two components is calculated from the length of water courses of the two types within a radius of $L_{w}$ of the focal population at $x$. It is assumed that intermittent water courses are replenished by rainfall at a rate determined by the parameter $\delta$, providing the same density of breeding habitat as permanent sites when rainfall is heavy. Mosquito carrying capacity increases at a rate determined by the parameter $\kappa$ as the density of both types of water body grows, the influence reaching an asymptote at $\alpha_{2}$.

\section{Mosquito aestivation}

Aestivation is modelled by supposing that there is a period in each year $\left(t_{A 1}, t_{A 2}\right)$ when mated females enter a dormant state with daily probability $\psi$, which they survive with probability $1-\mu_{E}$. If a female does survive, she emerges on a random day within a later period $\left(t_{A 3}, t_{A 4}\right)$, and resumes her normal activities.

\section{Long-distance migration}

Long distance migration is modelled by supposing that there is a period each year $\left(t_{D 1}, t_{D 2}\right)$ when mated females initiate migration from the north-east to the southwest with probability $d_{M}$ each day, and a second period $\left(t_{D 3}, t_{D 4}\right)$ when migration is from the south-west to the north east (migration is assumed to initiate with the same probability in each direction). The timing and direction of long-distance movement were chosen to reflect the annual wind patterns in this region [3]. A female survives migration with probability $1-\mu_{M}$, in which case the female moves to a new site chosen at random from a subregion of the simulation area that extends from the focal site in a NE $\rightarrow \mathrm{SW}$ direction (or vice versa) to the edge of the simulation area. The distribution of mean migration distances (in either direction) obtained from a model simulation with default parameters is plotted in Additional file 2 .

\section{Small permanent larval sites}

It is possible that there is a class of permanent breeding habitats that is always present, irrespective of rainfall, but are not of the size that are present in the permanent water body database (hereafter 'small permanent larval sites'). It is unclear whether this type of larval site is important to mosquito biology and in the basic version of the model they are assumed to be absent. The term $\alpha_{0}(x)$ in Eq. (1) is used to explore their effect on mosquito population persistence. It is assumed that small permanent sites are lognormally distributed across local populations with mean $\alpha_{0}^{\mu}$ and variance $\alpha_{0}^{\sigma^{2}}$.

\section{Model parameters}

All the model parameters and their default values are shown in Additional file 3. The demographic life-history parameters $\left(T_{L}, \mu_{J}, \mu_{A}, \theta\right)$ are taken from the literature [40-43]; Lambert et al. pers. comm.). The carrying capacity parameters $\left(\alpha_{0}, \alpha_{1}, \alpha_{2}, \phi, \kappa, \delta\right)$ were determined using mosquito population size estimates from three villages in the region (two in Burkina Faso and one in Mali) and through expert judgement. Further details and justification of the default parameters are provided in Additional file 4.

\section{Results \\ Local dispersal}

Consider first a version of the model where aestivation and long-distance migration do not occur, and there are no residual breeding habitats $\left(\psi=d_{L D M}=\alpha_{0}(x)=0\right)$. If the dispersal of mosquitoes between neighbouring settlements is also disallowed, so that the model represents a set of isolated populations, a majority ( 56\%) of settlements are without a local mosquito population after 10 years. Mosquitoes persist in the remaining settlements because they are adjacent to permanent water bodies, or because they are in locations where rainfall occurs throughout the year (in the southernmost part of the region), or both (Fig. 2; these settlements will henceforth be referred to as harbouring 'persistent 
populations'). Recall that field surveys find nearly all settlements have viable mosquito populations in the rainy season. The model thus suggests that local dispersal may be important to explain this observation.

Allowing local dispersal amongst settlements does result in more mosquito populations during the rainy season (Fig. 3). There is some information on local
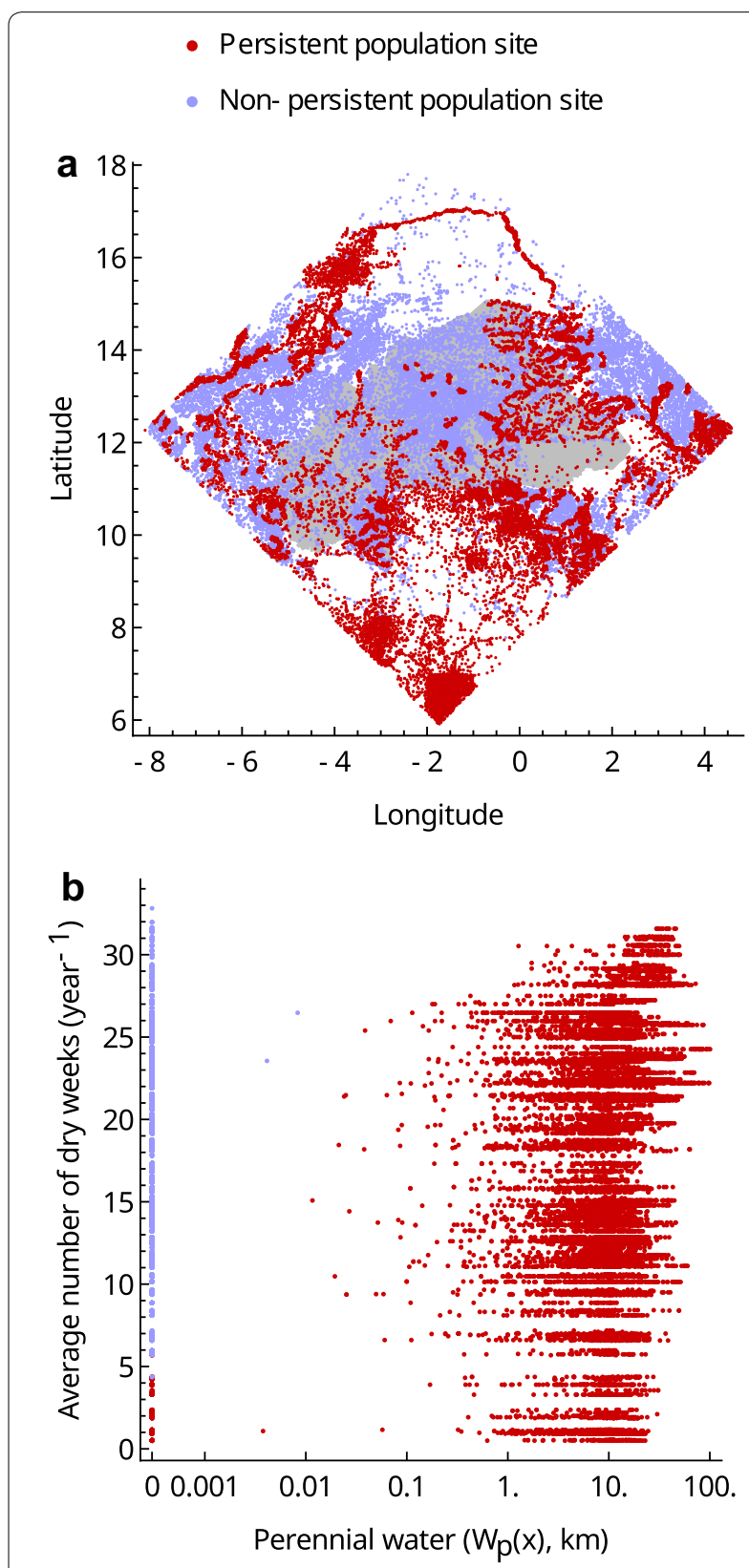

Fig. 2 The distribution (a) and characteristics (b) of settlements that, in the simulations, persist indefinitely in isolation (without immigration or aestivation; red points). Settlements where populations become extinct in these conditions are shown as blue dots

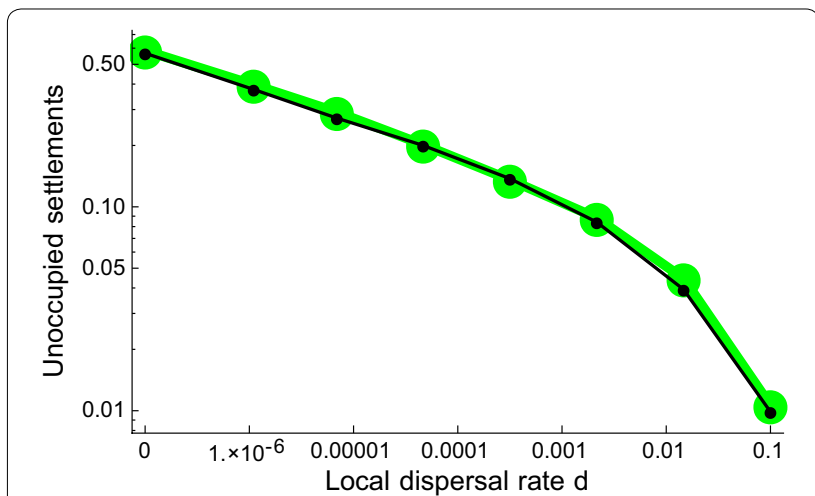

Fig. 3 The effect of local dispersal on the fraction of settlements that do not maintain a population during the wet season. The black line shows the results of the standard model for which adult mortality is constant irrespective of adult age, while the green line shows results of the same model except for an assumption that adults die at age 30 days if not before

dispersal rates in West Africa from mark-release-recapture experiments in The Gambia [44], Burkina Faso [45], and Mali [46]. In each study, a number of An. gambiae s.l. marked with fluorescent powder were released in one village with traps being placed in both the focal and neighbouring villages. From these experiments lifetime probabilities of movement between villages of between 0.04 and 0.24 were estimated. Assuming the default daily mortality rate of 0.125 these estimates translate to a rate of dispersal (the parameter $d$ ) of $0.005-0.034$.

With local dispersal rates of 0.005 the percentage of settlements without mosquitoes in the rainy season falls from $\sim 56$ to $\sim 5 \%$, and with dispersal rates of 0.034 to $\sim 2 \%$. However, to replicate observed patterns of mosquito populations (less than $1 \%$ settlements without mosquitoes in the rainy season) much higher local dispersal rates are required, approximately $10 \%$ of mosquitoes moving amongst settlements per day $(d=0.1)$, which seems unrealistically high.

Local dispersal might increase the numbers of settlements occupied during the rainy season by allowing persistent populations to act as sources of mosquitoes that colonise less favourable locations each season (sometimes called island-mainland metapopulation dynamics), or the dispersal may allow the existence of a "blinkinglight" or classical metapopulation where non-persistent populations often persist for several generations, sending out their own colonists, before going extinct. Both processes may occur simultaneously but examination of the model results suggests that the former is most important. The probability that a site is occupied during the rainy season is more correlated with its distance to the nearest persistent population than to the local density of 


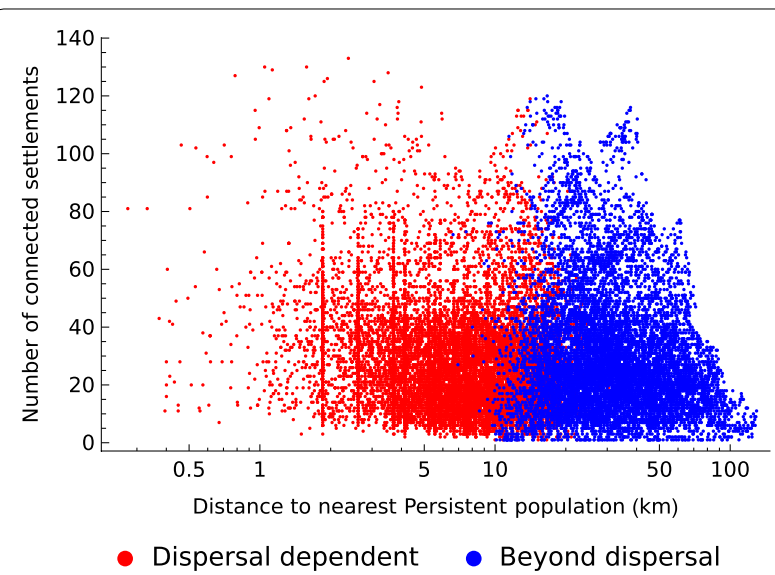

Fig. 4 The effect of proximity to a persistent population and the local density of settlements on settlement status. With dispersal $d=10^{-5}$ (and aestivation, migration, and small permanent larval habitat all turned off), the model predicts that $25 \%$ of settlements are regularly colonised in the wet season (red), and $31 \%$ are not (blue). The $x$-axis plots distance to the nearest of the remaining $44 \%$ of sites that are permanently occupied (even with no dispersal), and the $y$-axis plots the total number of sites within $10 \mathrm{~km}$ from the focal site

settlements (Fig. 4). In a classical metapopulation, higher settlement density tends to be correlated with occupation rates because of a network effect where nearby populations are able to rescue each other from extinction.

The basic implementation of the model assumes a constant mortality hazard (and hence an exponential survival curve) which means that when populations are high a small fraction of individuals survive for a long time, possibly through the dry season. The model was rerun assuming a maximum insect longevity of 30 days because of a concern that these very old mosquitoes, an artefact of the survival function assumption, might affect the mosquito distribution. This change had a negligible effect on population incidence (Fig. 3).

If the local dispersal parameter, $d$, is 0.01 , which is in the middle of the range of the mark-recapture estimates described above, the number of settlements that remain unoccupied in the rainy season each year varies between 1500 and 2000 ( $\sim \%$ of all settlements). These are mainly confined to the northern part of the simulation region (Fig. 5). Though there have been fewer surveys of mosquitoes in the north compared to the south of the region, those that have been carried out have found viable populations of An. gambiae s.l. in all settlements that were sampled (Fig. 5). The model is now used to explore the three non-exclusive hypotheses to explain the persistence of these populations: aestivation, long distance migration, and residual permanent breeding habitat.

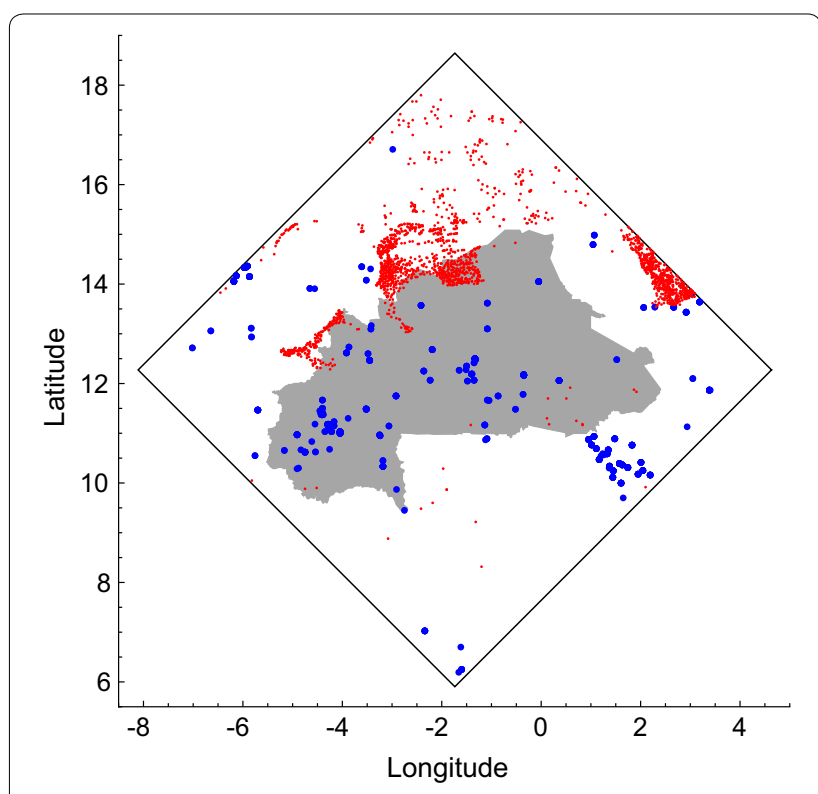

- Settlements where populations do not persist despite high dispersal $(d=0.01)$

- Field surveys observing presence of An. gambiae or An. coluzzii

Fig. 5 Red points mark settlements where the simulations predict populations cannot persist despite frequent local dispersal $(d=0.01)$, if there is no aestivation, migration, or unknown permanent breeding habitat. Blue points mark the locations of field studies, of which all have identified the presence of An. gambiae or An. coluzzii

\section{Aestivation}

The effect of aestivation on the proportion of settlements with rainy season mosquito populations is shown in Fig. 6 for three different assumptions about the extent of local dispersal between settlements. An increasing propensity to aestivate, and higher survival over the dry season, both lead to more rainy season mosquito populations. For example, when one in 100 mosquitoes enter aestivation per day, and $10 \%$ survive the dry season, the percentage of settlements without rainy season mosquitoes drops to around $1 \%$, as long as there is some local dispersal. However, further aestivation does little to reduce this percentage and the number of unoccupied sites does not drop below 300 for any of the parameter combinations shown in Fig. 6.

Aestivation has the greatest effect on mosquito population dynamics in more arid areas. Figure 7 plots those settlements which, if moderate amounts of dispersal are assumed, only have rainy season populations in the presence of mosquito aestivation. The populations are concentrated in an arid area of the Burkina Faso-Mali border, and further east at the edge of the study region in Niger. Also shown in the figure, in blue, are the remaining 300 settlements with no mosquito populations. These 

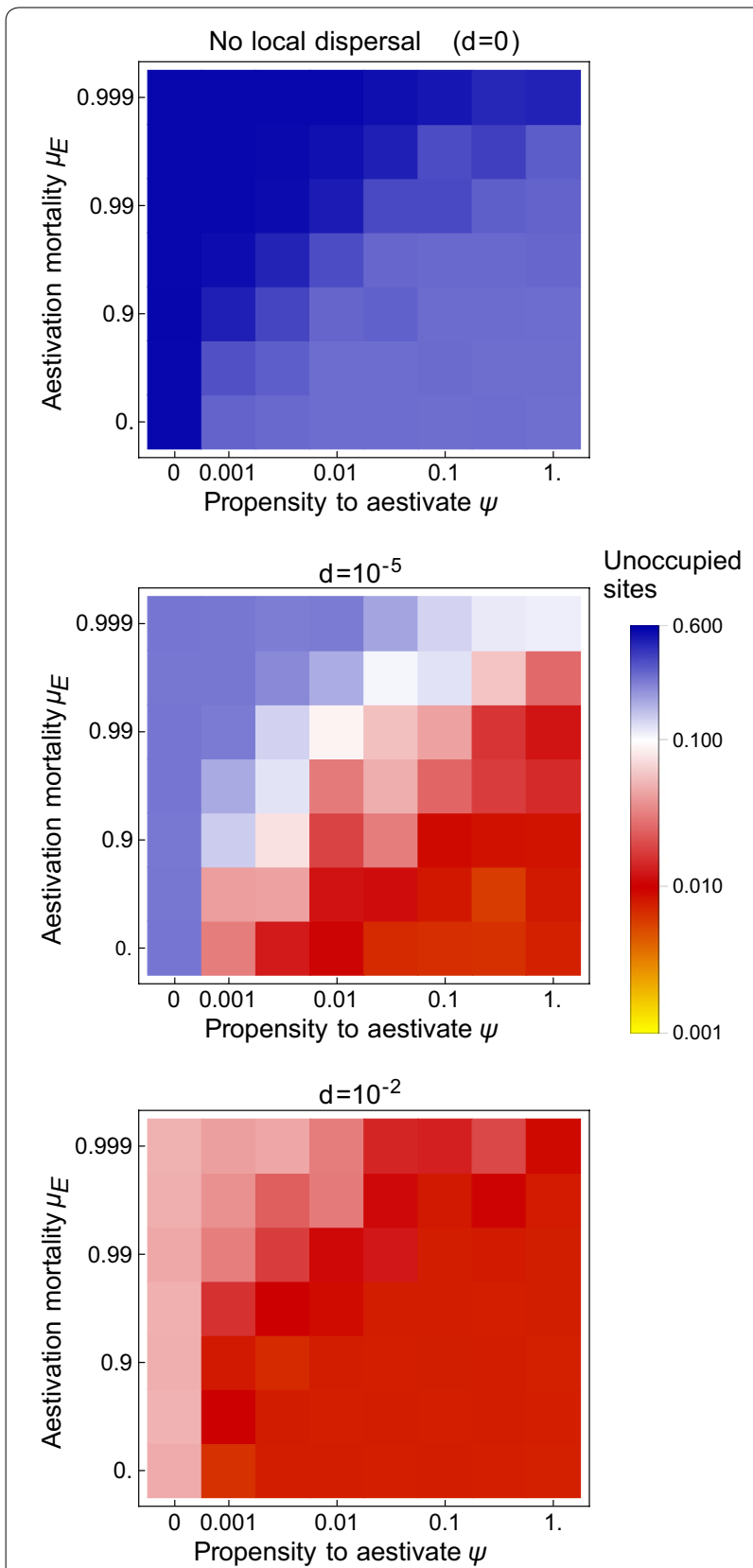

Fig. 6 The effect of aestivation on population incidence during the late rainy season (on the 19th October), if aestivation and local dispersal are the only processes supporting dry season persistence

are chiefly in central Mali, an area that is both the driest in the region (and without permanent water bodies) and also with the sparsest pattern of human settlement (Fig. 1).

\section{Migration}

The fraction of settlements in the region without mosquito populations during the rainy season declines if long-distance migration is permitted (Fig. 8). If the

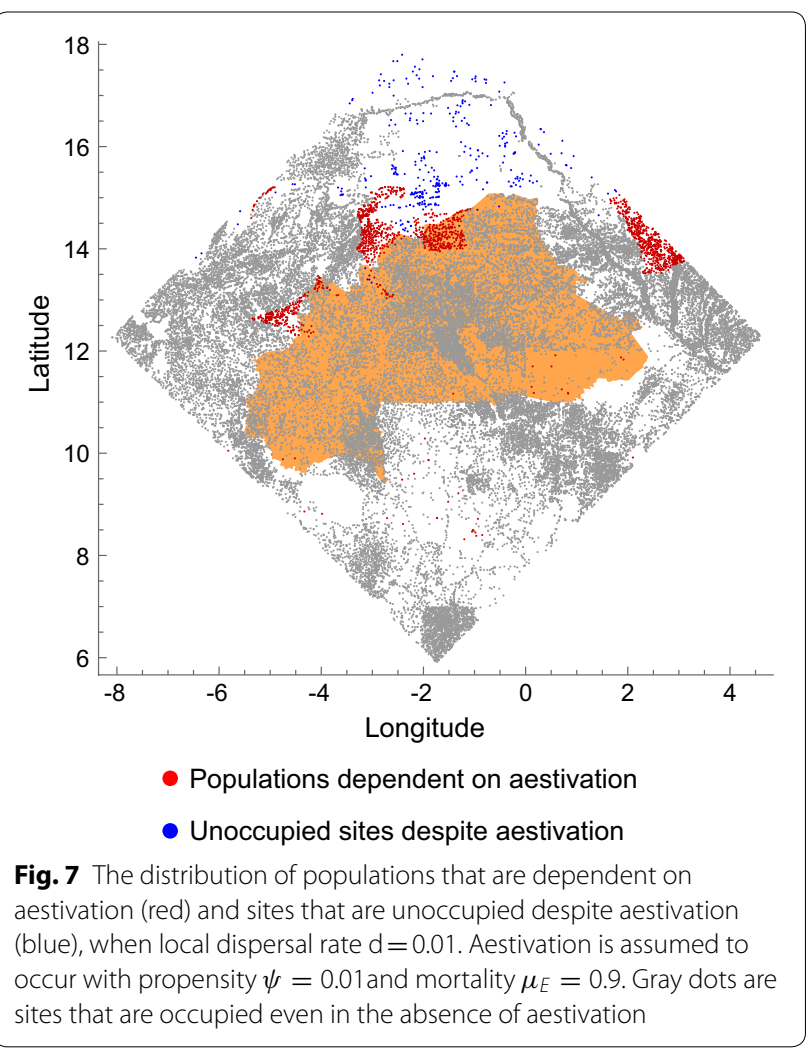

propensity to migrate and the probability of surviving migration are high enough, every settlement is colonised during the rainy season, even those in the most arid part of the north of the study region (Fig. 9).

\section{Small permanent larval sites}

Unsurprisingly, increasing the average amount of assumed permanent habitat leads to more settlements having mosquitoes during the rainy season (Fig. 10). If enough of this habitat exists, widespread rainy season populations can be explained. Increasing variance tends to reduce rainy season incidence though in the absence of local dispersal, both the mean and variance have to be high to make a major difference. When mosquitoes are allowed to disperse locally, and more settlements are occupied during the rainy season, increasing variance can mitigate some of the effects of lower mean levels of small permanent breeding habitat. This appears to occur because some habitations have large mosquito populations that are able to colonise other settlements in the vicinity.

Effects of dry season ecology on local population dynamics Periodic surveys of mosquito abundance allow local population fluctuations to be observed in the field, and have been used to investigate how specific populations might be maintained $[8,12]$. The model is now used to examine 

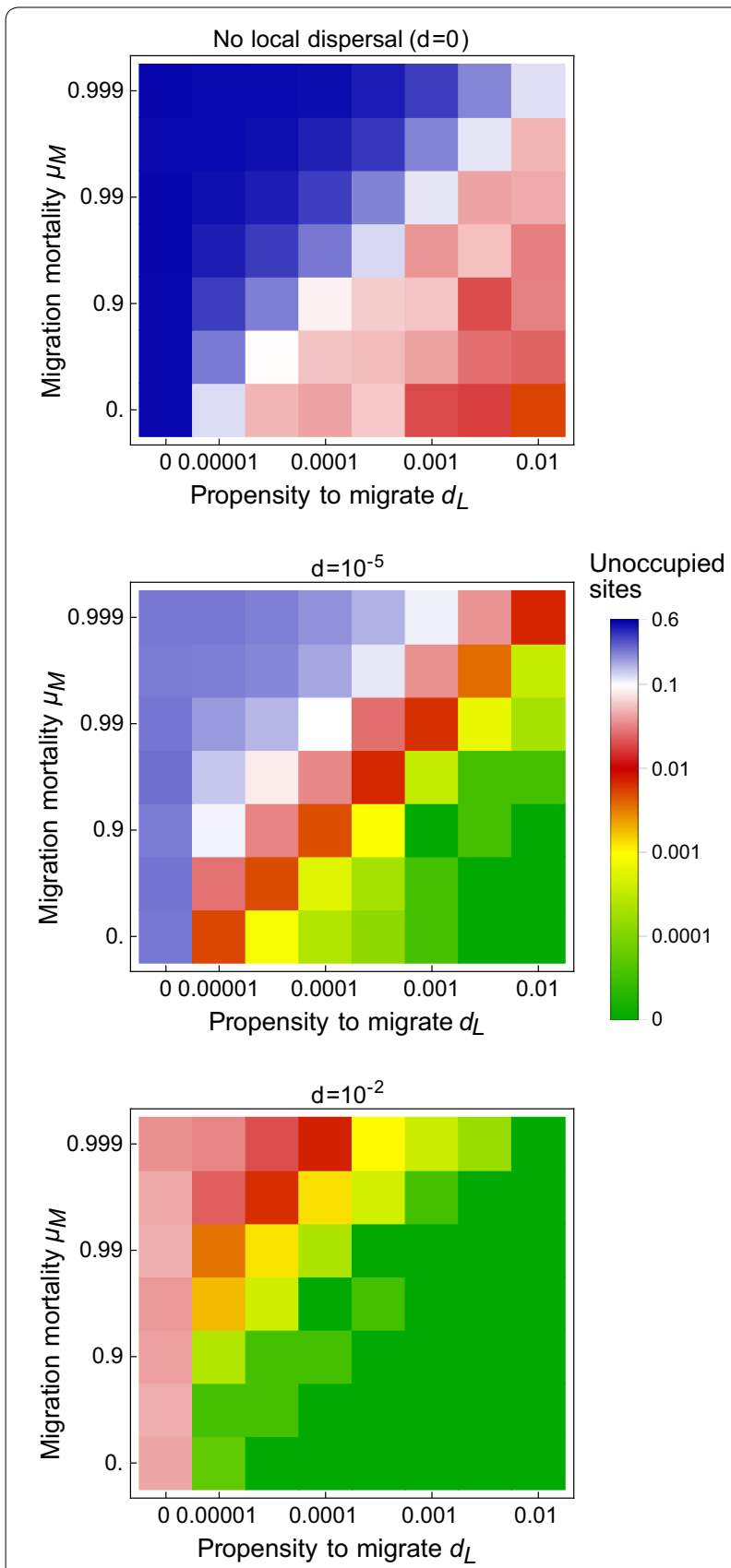

Fig. 8 The effect of migration on (rainy season) population incidence if migration and local dispersal are the only processes supporting local persistence (cf. Fig. 6)

how the different dry season hypotheses influence local population dynamics.

For a given parameterisation, simulations predict that there is substantial variation among sites in the timing of population growth at the start of the rainy season, and in the numbers of mosquitoes present in the dry season (if there are any). Despite this variation, there are consistent

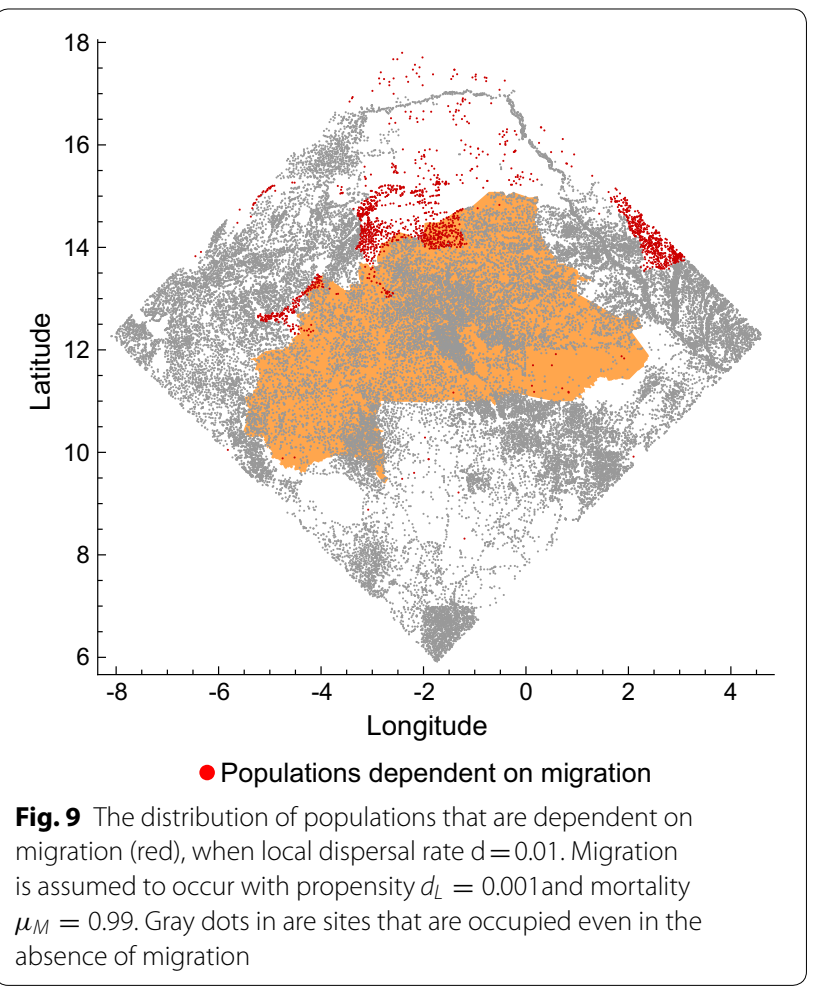

patterns in the population dynamics depending on whether persistence is maintained by aestivation, migration, or by small permanent larval sites (shown in Fig. 11). If aestivation is important, the number of active females increases rapidly at the start of the rainy season at approximately the same time across sites. If migration is more important, the population growth phase tends to be later (by up to a month), though there is considerable variation in timing across sites, reflecting the highly stochastic nature of colonisation by females migrating long distances. If a population persists because of the presence of permanent larval habitat, active adult mosquitoes will be present throughout the dry season albeit at very low numbers. In this case population growth occurs early but slowly at the very beginning of rainy season, so that there is a less distinct spurt after the first major rain. These differences are most evident in sites that are distant from persistent populations, where the effects of local dispersal per se are less important.

\section{Discussion}

This study explores the factors allowing the continued presence of mosquito populations in West African locations where larval habitat is scarce for many months each year. Computer simulations cannot of course prove which processes are involved but are important for exploring hypotheses and guiding empirical work.

The simulation results suggest that local dispersal amongst settlements is important in maintaining 

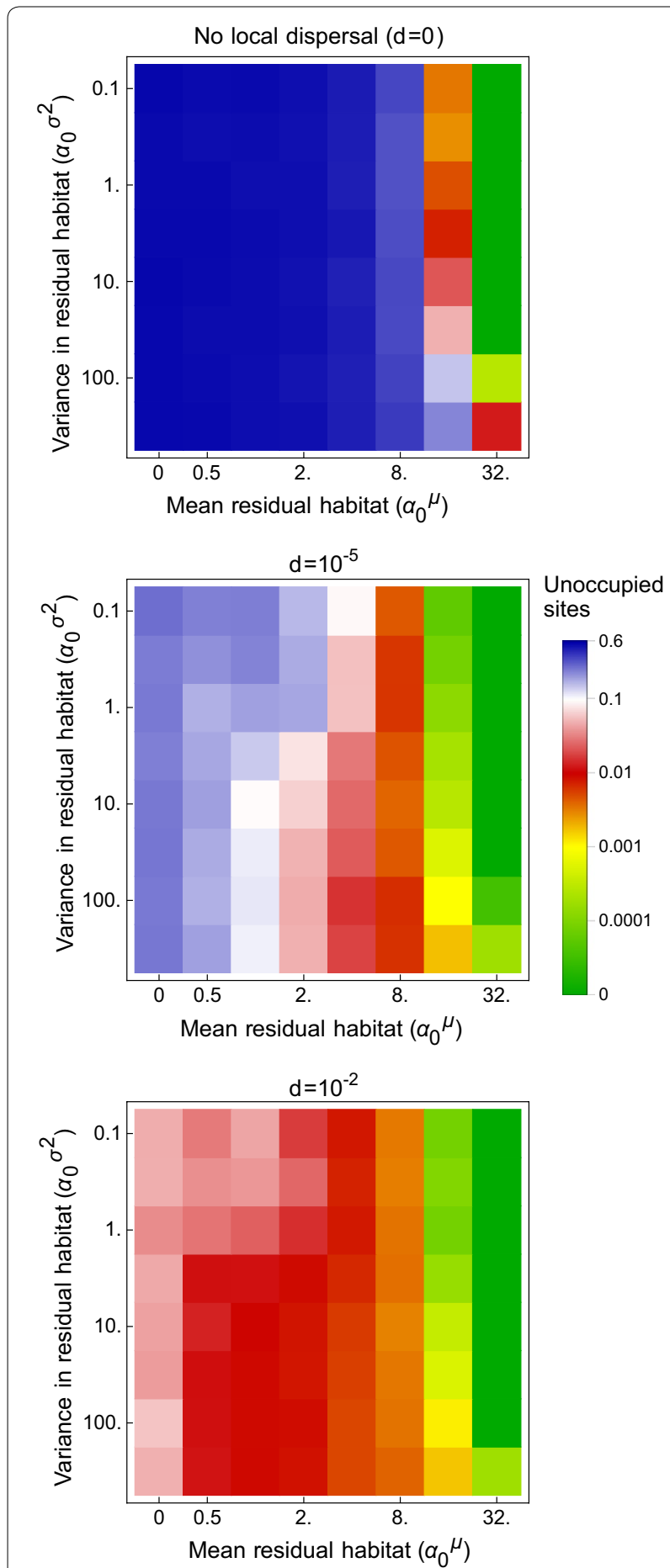

Fig. 10 The effect of assuming there are small permanent larval sites (and neither aestivation nor migration) on (rainy season) population incidence

mosquito populations in the rainy season right across the study region. Extinction during the dry season occurs relatively frequently and without local dispersal there are no insects present to exploit breeding opportunities at the start of the rainy season. There have been some estimates of local dispersal rates from a limited number of mark-release-recapture experiments [44-46] and these seem to be high enough to explain why mosquitoes are present during the rainy season across most of the study area. However, further experimental and possible genetic data would be valuable to confirm this conclusion.

Even if local movements are very frequent, the model predicts that there are settlements in the Sahelian part of the study area which should not have viable mosquito populations in the rainy season. Though there have been fewer field surveys in the arid north of the study region compared to the south, those that have been conducted regularly record mosquitoes in the rainy season [2] (and similarly in other parts of the Sahel outside the simulation area (e.g. $[8,14]))$. This suggests that there is more to population persistence than local dispersal alone, a conclusion also reached by entomologists after studying mosquito autecology [8]. Small permanent larval sites, absent from the water-course data base used to build the model, might have a widespread presence during the dry season. There are many types of largely man-made larval sites that fall in this category including wells and other water containers, and small reservoirs which can be found on perennial streams in Burkina Faso [47]. In East Africa, An. gambiae s.l. larvae have been found in a wide range of man-made water bodies, including sewage ponds and drains in the urban environment of Dar es Salaam [48], artificial containers and holes on a rural island in Lake Victoria [49], and cement-lined pits in a rural town next to Lake Victoria [50]. Unfortunately, no general surveys of the distribution and significance of small man-made larval sites in West Africa were available. Even if quite rare, the model found they can explain the maintenance of viable populations during the dry season. However, several field studies investigating the dry season ecology of An. gambiae s.l. conducted extensive surveys for potential larval sites without finding them (e.g. [11, 12]). Though some cryptic larval sites will affect mosquito population dynamics, it appears unlikely that their existence is by itself a complete explanation for all extant rainy-season populations. A number of previous large-scale models of mosquito dynamics in Africa have assumed there is a low background rate of recruitment into the adult population during the dry season (presumably from larvae in rare small water bodies) [31-33].

Evidence of $A n$. gambiae s.l. aestivation dates back to the late 1960s $[9,10]$ and more recently a number of studies have reported this behaviour in some $A n$. coluzzii populations [8, 11-15]. However, except for one mark-release-recapture experiment that caught a single female mosquito that had been marked in the previous rainy season (some 7 months earlier, [11]), the evidence 

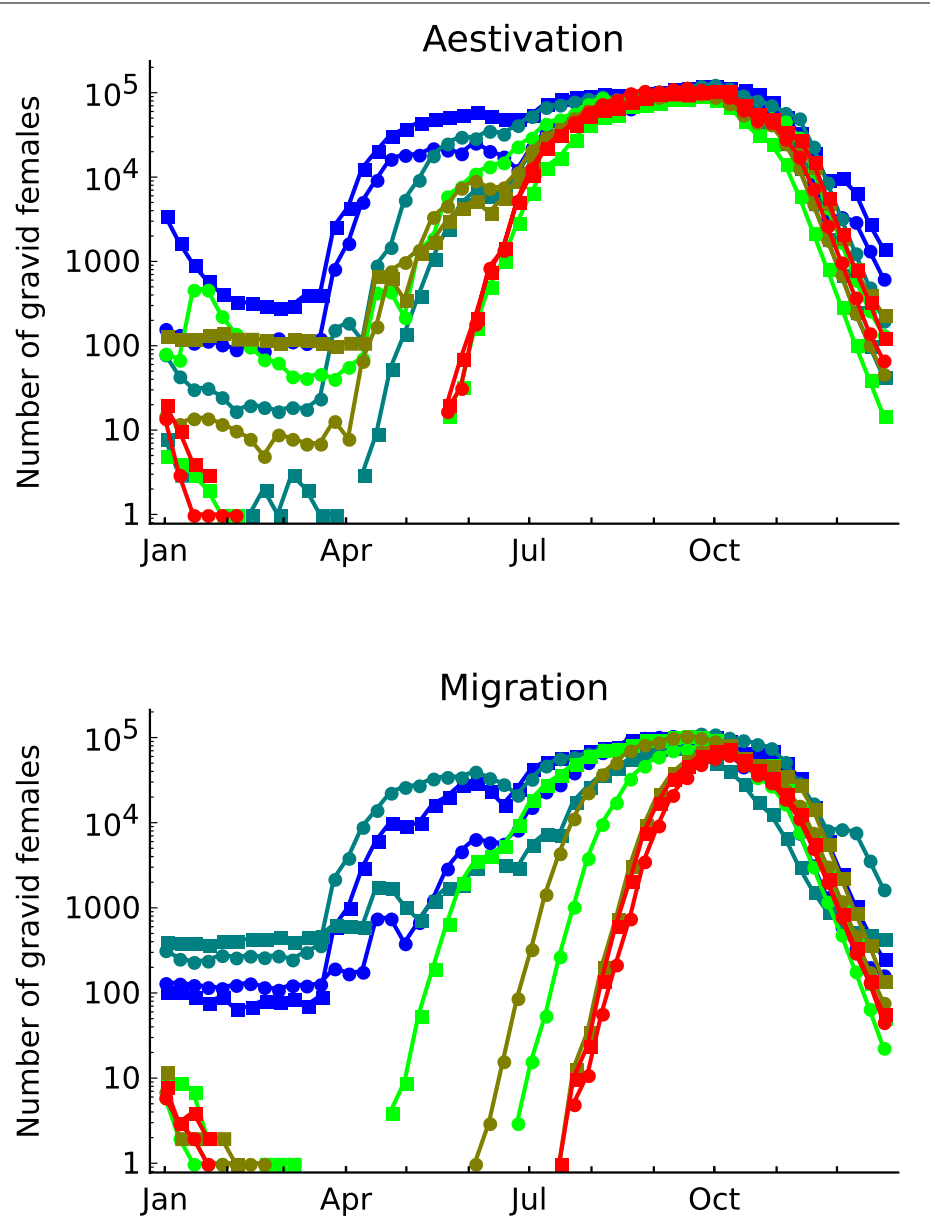

\section{Distance from a persistent population}
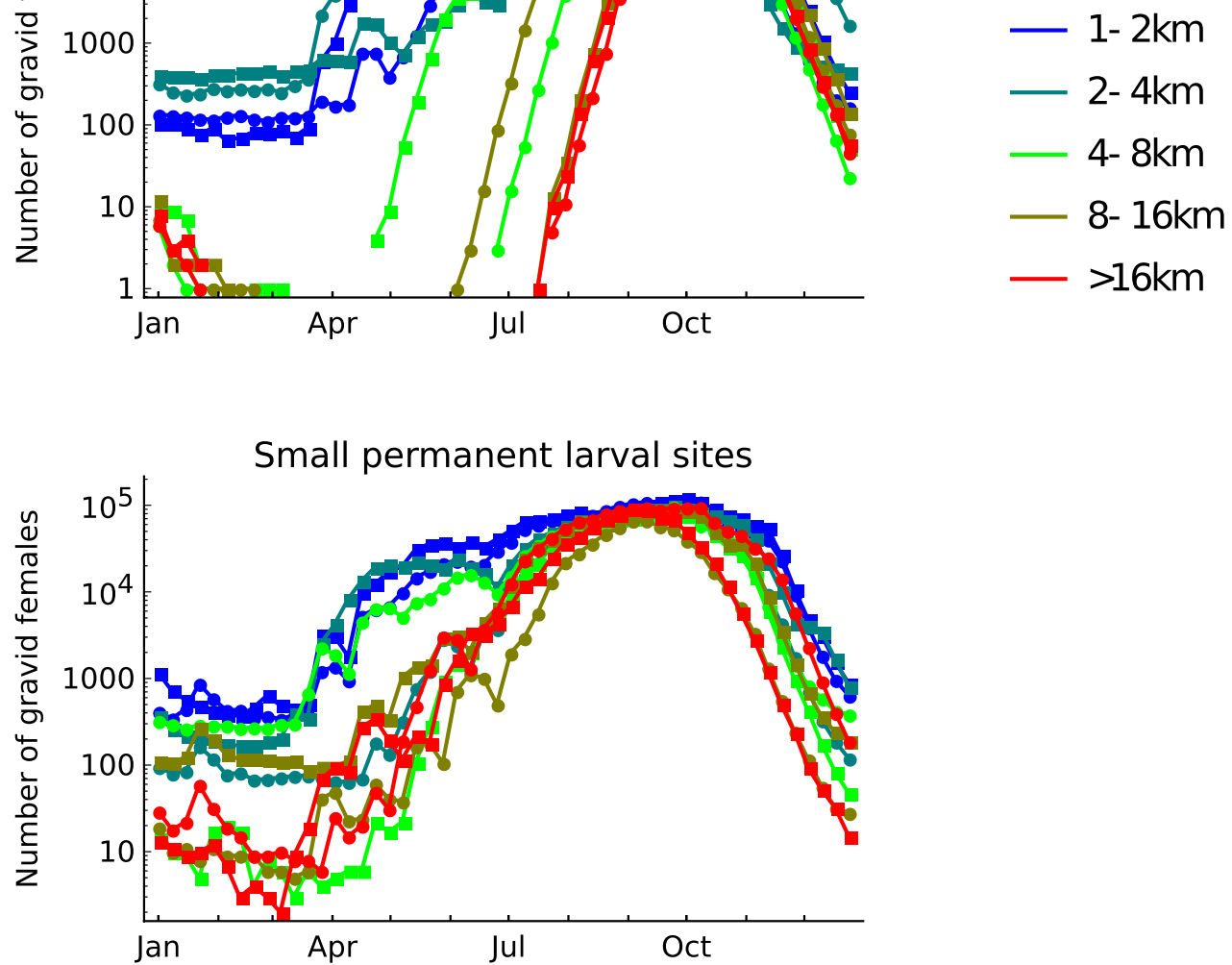

Fig. 11 Local dynamics at random selected sites depending on dry season ecology and the distance of the site to a persistent population. Aestivation parameters are $\psi=10^{-3}, \mu_{E}=0.9$, migration parameters are $d_{L}=10^{-5}, \mu_{M}=0.99$, and small permanent larval site parameters are $\alpha_{0}^{\mu}=4, \alpha_{0}^{\sigma^{2}}=10$

is indirect, being based on measurements of phenotypic traits $[9,10,13,14]$, time-series of trap data $[8,12]$, or genetic analyses [15].
Incorporating aestivation into the model led to rainyseason populations in most locations, but not in the most northern (Sahelian) locations which have the 
lowest rainfall and the longest dry seasons. This is, in part, because populations do not become large in these locations due to the low rainfall even in the rainy season. However, it is possible that the current model understates the potential for population growth during the rainy season in the Sahel, where mosquito predation is generally lower than in locations with persistent mosquito populations (T. Lehmann, pers. comm.). Furthermore, mosquitoes are thought to use rainfall cues, in particular to time their emergence from aestivation after the first big rain of the year (T. Lehmann, pers. comm.), a strategy that is likely to be selected in a region such as the Sahel with considerable year to year variation in when the rainy season starts [3]. An interesting extension of this work will be to investigate whether more detailed models of aestivation, that incorporate these factors, would affect the conclusions. Unfortunately, at present too little is known about aestivation behaviour to explore such behaviours. Other large-scale models have assumed that a small number of adult mosquitoes enter an age class (more than 44 days old) with relatively low mortality and which allows some to survive the dry season by, in effect, aestivating [34,35]. They too find aestivation can help explain rainy-season mosquito populations.

Evidence for long-distance migration of An. gambiae s.l., like that for aestivation, is indirect and based on survey data [8] and genetic [15] analyses. The available information is thus limited and long-distance migration was incorporated in this model in a deliberately simple way based on broad seasonal patterns of air flow that can be revised as more is discovered. However, the simulations suggest that relatively low levels of long distance movement by mated females could give rise to most settlements being occupied during the rainy season. Further study of long-distance movement would be very informative.

It is not necessary for mosquitoes to aestivate in every settlement, or for each to be recolonised by long-distance migrants, to obtain widespread rainy season populations. As long as there is some local dispersal, the model simulations showed that populations that successfully survive the dry season through aestivation or are recolonised by long-distance migrants can seed other populations in their vicinity where neither occurred. It may be possible to detect this effect by looking at the detailed timing of rainy-season resurgence as a function of local settlement density and connectedness, though such data is not currently available. The three hypotheses explored in this study give rise to different patterns of local population dynamics, particularly in those settlements that are some distance from persistent populations (Fig. 11). In these settlements there may be substantial variability in dynamics between years, regardless of the dry season ecology, so that inferences of the dry season ecology from survey data alone will require good quality data spanning multiple years. However, such data are relatively easy to collect by field entomologists, and this approach has been used to investigate dry season anopheline behaviour in a Sahelian village in Mali [8]. Analysis of the time-series reported in this study and comparison with the model outputs are most indicative of aestivation in the case of An. coluzzii and migration in the case of An. gambiae and $A n$. arabiensis [8]. Of course, the three hypotheses are not mutually exclusive. In the study village used by [8], more recent genetic evidence has suggested that $A n$. coluzzii populations both aestivate and are reinforced by migrants [15]. Simulations including multiple factors in general found their effects combined additively except that aestivation made little further difference in the presence of rare dry-season larval sites (see Additional file 5).

The model presented in this paper is particularly motivated by the biology of An. gambiae and its closely related and morphologically indistinguishable sister species $A n$. coluzzii, both of which show strong anthropophily [21, 27-30]. This is the basis of the assumption that the spatial distribution of mosquito populations corresponds to the pattern of human settlement. There is a further morphological indistinguishable species of the An. gambiae complex, An. arabiensis, which is also a significant vector of malaria in the region. This species varies in its degree of anthropophily [21] though appears to be more associated with humans in the West African part of its range [51]. It is found in drier environments compared with An. gambiae and An. coluzzii, though even less is known about its aestivation and migration behaviour. There are further subtle differences in the ecology of these three closely related species [22-25] that would be interesting to include in future versions of the model. For instance it is well established that An. coluzzii more than An. gambiae is able to exploit large irrigated fields, in particular rice paddies, as breeding sites [6]. However, based on current understanding of the ecology of the three species it has not been possible to develop species-specific versions of the model hence the decision to work with a generic Anopheles model.

As mentioned in the introduction, the current model deliberately omits some aspects of mosquito biology to reduce the times it takes to run the simulation and to allow us to concentrate on broad spatial patterns. In particular, it is assumed that temperature and humidity do not directly influence mosquito survival and development (though rainfall of course is a major driver of habitat availability). The modelling approach can easily be extended to allow weather-dependent mosquito 
demographic parameters. It would also be possible to include a more sophisticated representation of rainfall. At present it is assumed that the number of larval sites increases with rainfall though it is known that heavy rain can, in some environments, be detrimental to mosquitoes as it flushes out their larval larval sites [52]. Further developments could include modelling the movement of water downstream and the creation of larval larval sites as streams turn into pools when rainfall or water flow decreases [53]. It would also be possible to study multi-annual climate variation, for instance consecutive years with above or below average rainfall. Analysis of 200 years of historical precipitation data has shown that there is significant autocorrelation in annual rainfall in this region [3]. The challenge is not so much building the model (though these refinements come at computational expense) as estimating its parameters. Models of this type may be helpful in exploring the timing of specific control measures.

Relatively little is known about local and long-distance dispersal, density dependent processes, adult longevity and aestivation in the An. gambiae complex. New information on all these aspects would greatly improve the ability to model mosquito spatial population dynamics.

One type of data that has become much more readily available recently is high resolution geographical data, such as the human settlement, water course and rainfall information that was incorporated in the model. It is likely that the (OCHA) settlement data used here does not include all human settlements in the region. Comparison with satellite data from the Center for International Earth Science Information Network (CIESIN; http:// www.ciesin.org/data/hrsl/) suggests that the OCHA data includes all large villages and towns where the two data coincide (CIESIN data is currently available for Burkina Faso, Ghana, and Côte d'Ivoire, though coverage is not complete), but not all small settlements. This suggests that the current model may underestimate connectivity between settlements and, therefore, may underestimate the persistence of mosquito populations. The quality of geographical data-from satellite imagery and other methods-is likely to improve; for example, databases on human settlement will increasingly include richer information about their size and economic development, and possibly even directly relevant variables such as bed net use.

Distinguishing between these hypotheses is important in improving current and developing new methods of mosquito control. For example, were aestivation to be the predominant mode of dry season survival then it might be possible to target vulnerable mosquitoes in their aestivation sites [11]. If long-distance migration is important than novel control proposals such as the use of gene drive introduced into source populations may prove highly effective. In general the individual-based nature of the current model makes it straightforward to adapt to study novel methods of vector control such as gene drive.

\section{Conclusions}

The modelling described here has allowed investigation of the common explanations for the persistence of mosquito populations in West Africa. In much of the study area, the analysis suggests that persistence is the result of mosquitoes dispersing locally from source populations, where there is year-round breeding habitat, into settlements that otherwise would not support populations. However, the extent of this explanation depends critically on the frequency with which mosquitoes move amongst neighbouring populations, of which there remains great uncertainty. Further experimental and genetic studies are much needed.

The model simulations also suggest that some populations are not maintained only by the local dispersal of mosquitoes from populations with year-round breeding habitat, even if local dispersal is very frequent. Both aestivation and long distance migration were investigated, and the model predicted that migration is able to replicate vector persistence in all locations under certain conditions, yet aestivation is not. The failure of aestivation occurred in the driest and remotest locations where populations, if they exist, remain small. Further modelling will help to identify how aestivation behaviour can explain persistence in these locations. These results identify regions where field work to determine dry season persistence may be more efficacious. The model described in this paper can be extended in a number of directions, and thus applied to further issues in vector biology.

\section{Additional files}

Additional file 1. The seasonal and spatial trends in rainfall across the simulation area.

Additional file 2. Showing the distributions of local dispersal and migration distances across the simulation area.

Additional file 3. Model parameters and default values.

Additional file 4. Describing how the default parameters were set.

Additional file 5. The effects of combining dry season survival hypotheses (aestivation, migration and small permanent larval sites) on vector persistence across the simulation area.

Authors' contributions

AN and HCJG conceived the study. AN designed the model, performed the analysis, and wrote the paper, with inputs from HCJG. Both authors read and approved the final manuscript. 


\section{Acknowledgements}

We thank Tovi Lehmann, Ben Krajacich, Roy Faiman, and Austin Burt for very helpful comments that greatly improved the manuscript. The authors are supported by a grant from the Bill \& Melinda Gates Foundation. We would like to acknowledge the use of the University of Oxford Advanced Research Computing (ARC) facility in carrying out this work. http://dx.doi.org/10.5281/ zenodo. 22558

\section{Competing interests}

The authors declare that they have no competing interests.

\section{Availability of data and materials}

The datasets analysed during the current study are publicly available in: (1) the Humanitarian Data Exchange (human settlement data; https://data.humda ta.org/); (2) Digital Chart of the World (DCW) (water course data; available from http://www.diva-gis.org/Data); (3) European Centre for Medium-Range Weather Forecasts (https://www.ecmwfint/en/forecasts/datasets/reanalysis -datasets/era-interim; [39]).

\section{Consent for publication}

Not applicable.

Ethics approval and consent to participate

Not applicable.

\section{Funding}

The authors are supported by a grant from the Bill \& Melinda Gates Foundation. This funding body has had no direct role in the design of the study nor in the collection, analysis, interpretation of data and in writing of the manuscript.

\section{Publisher's Note}

Springer Nature remains neutral with regard to jurisdictional claims in published maps and institutional affiliations.

Received: 9 December 2017 Accepted: 21 March 2018

Published online: 02 April 2018

\section{References}

1. Bhatt S, Weiss DJ, Cameron E, Bisanzio D, Mappin B, Dalrymple U, et al. The effect of malaria control on Plasmodium falciparum in Africa between 2000 and 2015. Nature. 2015;526:207-11.

2. Wiebe A, Longbottom J, Gleave K, Shearer FM, Sinka ME, Massey NC, et al. Geographical distributions of African malaria vector sibling species and evidence for insecticide resistance. Malar J. 2017:16:85.

3. Nicholson SE. The West African Sahel: a review of recent studies on the rainfall regime and its interannual variability. ISRN Meteorology. 2013;2013:453521.

4. Ramsdale CD, Fontaine RE. Ecological investigations of Anopheles gambiae and Anopheles funestus. Geneva: World Health Organization; 1970.

5. Molineaux L, Gramiccia G. The Garki project: research on the epidemiology and control of malaria in the Sudan savanna of West Africa. Geneva: World Health Organization; 1980.

6. Touré YT, Petrarca V, Traore SF, Coulibaly A, Maiga HM, Sankare O, et al. The distribution and inversion polymorphism of chromosomally recognized taxa of the Anopheles gambiae complex in Mali, West Africa. Parassitologia. 1998;40:477-511.

7. Dery DB, Brown C, Asante KP, Adams M, Dosoo D, Amenga-Etego S, et al. Patterns and seasonality of malaria transmission in the forest-savannah transitional zones of Ghana. Malar J. 2010:9:314.

8. Dao A, Yaro AS, Diallo M, Timbiné $S$, Huestis DL, Kassogué Y, et al. Signatures of aestivation and migration in Sahelian malaria mosquito populations. Nature. 2014;516:387-90.

9. Omer SM, Cloudsley-Thompson JL. Survival of female Anopheles gambiae Giles through a 9-month dry season in Sudan. Bull World Health Organ. 1970;42:319-30

10. Omer SM, Cloudsley-Thompson JL. Dry season biology of Anopheles gambiae Giles in the Sudan. Nature. 1968;217:879-80.
11. Lehmann T, Dao A, Adamou A, Kassogue Y, Diallo M, Sékou T, et al. Aestivation of the African malaria mosquito, Anopheles gambiae in the Sahel. Am J Trop Med Hyg. 2010;83:601-6.

12. Adamou A, Dao A, Timbine S, Kassogué Y, Diallo M, Traoré SF, et al. The contribution of aestivating mosquitoes to the persistence of Anopheles gambiae in the Sahel. Malar J. 2011;10:151.

13. Yaro AS, Traoré Al, Huestis DL, Adamou A, Timbiné S, Kassogué Y, et al. Dry season reproductive depression of Anopheles gambiae in the Sahel. J Insect Physiol. 2012:58:1050-9.

14. Huestis DL, Yaro AS, Traoré Al, Dieter KL, Nwagbara Jl, Bowie AC, et al. Seasonal variation in metabolic rate, flight activity and body size of Anopheles gambiae in the Sahel. J Exp Biol. 2012;215:2013-21.

15. Lehmann T, Weetman D, Huestis DL, Yaro AS, Kassogue Y, Diallo M, et al. Tracing the origin of the early wet-season Anopheles coluzzii in the Sahel. Evol Appl. 2017;10:704-17

16. Jawara M, Pinder M, Drakeley CJ, Nwakanma DC, Jallow E, Bogh C, et al. Dry season ecology of Anopheles gambiae complex mosquitoes in The Gambia. Malar J. 2008;7:156.

17. Charlwood JD, Vij R, Billingsley PF. Dry season refugia of malaria-transmitting mosquitoes in a dry savannah zone of east Africa. Am J Trop Med Hyg. 2000;62:726-32.

18. Minakawa N, Githure JI, Beier JC, Yan G. Anopheline mosquito survival strategies during the dry period in western Kenya. J Med Entomol. 2001;38:388-92.

19. Garrett-Jones C. The possibility of active long-distance migrations by Anopheles pharoensis Theobald. Bull World Health Organ. 1962:27:299-302.

20. Coetzee M. Distribution of the African malaria vectors of the Anopheles gambiae complex. Am J Trop Med Hyg. 2004;70:103-4

21. Sinka ME, Bangs MJ, Manguin S, Coetzee M, Mbogo CM, Hemingway $J$, et al. The dominant Anopheles vectors of human malaria in Africa, Europe and the Middle East: occurrence data, distribution maps and bionomic précis. Parasit Vectors. 2010;3:117.

22. Fossog B, Ayala D, Acevedo P, Kengne P, Ngomo Abeso Mebuy I, Makanga $B$, et al. Habitat segregation and ecological character displacement in cryptic African malaria mosquitoes. Evol Appl. 2015;8:326-45

23. Costantini C, Ayala D, Guelbeogo WM, Pombi M, Some CY, Bassole IHN, et al. Living at the edge: biogeographic patterns of habitat segregation conform to speciation by niche expansion in Anopheles gambiae. BMC Ecol. 2009;9:16

24. Simard F, Ayala D, Kamdem GC, Pombi M, Etouna J, Ose K, et al. Ecological niche partitioning between Anopheles gambiae molecular forms in Cameroon: the ecological side of speciation. BMC Ecol. 2009;9:17.

25. Gimonneau G, Pombi M, Choisy M, Morand S, Dabiré RK, Simard F. Larval habitat segregation between the molecular forms of the mosquito Anopheles gambiae in a rice field area of Burkina Faso, West Africa. Med Vet Entomol. 2012;26:9-17

26. Judson OP. The rise of the individual-based model in ecology. Trends Ecol Evol. 1994;9:9-14.

27. Coluzzi M, Sabatini A, Petrarca V, Di Deco MA. Chromosomal differentiation and adaptation to human environments in the Anopheles gambiae complex. Trans R Soc Trop Med Hyg. 1979:73:483-97.

28. Garrett-Jones C, Boreham PFL, Pant CP. Feeding habits of anophelines (Diptera: Culicidae) in 1971-78, with reference to the human blood index: a review. Bull Entomol Res. 1980;70:165-85.

29. Costantini C, Sagnon NF, della Torre A, Diallo M, Brady J, Gibson G, et al. Odor-mediated host preferences of West African mosquitoes, with particular reference to malaria vectors. Am J Trop Med Hyg. 1998;58:56-63.

30. Besansky NJ, Hill CA, Costantini C. No accounting for taste: host preference in malaria vectors. Trends Parasitol. 2004;20:249-51.

31. Hoshen MB, Morse AP. A weather-driven model of malaria transmission. Malar J. 2004;3:32

32. Ermert $V$, Fink $A H$, Jones AE, Morse AP. Development of a new version of the Liverpool Malaria Model. I. Refining the parameter settings and mathematical formulation of basic processes based on a literature review. Malar J. 2011;10:35.

33. Ermert $\mathrm{V}$, Fink $A H$, Jones $A E$, Morse AP. Development of a new version of the Liverpool Malaria Model. II. Calibration and validation for West Africa. Malar J. 2011;10:62. 
34. Lunde TM, Korecha D, Loha E, Sorteberg A, Lindtjørn B. A dynamic model of some malaria-transmitting anopheline mosquitoes of the Afrotropical region. I. Model description and sensitivity analysis. Malar J. 2013;12:28.

35. Lunde TM, Balkew M, Korecha D, Gebre-Michael T, Massebo F, Sorteberg A, et al. A dynamic model of some malaria-transmitting anopheline mosquitoes of the Afrotropical region. II. Validation of species distribution and seasonal variations. Malar J. 2013;12:78.

36. Depinay J-MO, Mbogo CM, Killeen G, Knols B, Beier J, Carlson J, et al. A simulation model of African Anopheles ecology and population dynamics for the analysis of malaria transmission. Malar J. 2004;3:29.

37. North A, Burt A, Godfray HCJ. Modelling the spatial spread of a homing endonuclease gene in a mosquito population. J Appl Ecol. 2013:50:1216-25.

38. Eckhoff PA, Wenger EA, Godfray HCJ, Burt A. Impact of mosquito gene drive on malaria elimination in a computational model with explicit spatial and temporal dynamics. Proc Natl Acad Sci USA. 2016;114:E255-64.

39. Dee DP, Uppala SM, Simmons AJ, Berrisford P, Poli P, Kobayashi S, et al. The ERA-Interim reanalysis: configuration and performance of the data assimilation system. Quart J R Meteor Soc. 2011;137:553-97.

40. Gary RE, Foster WA. Effects of available sugar on the reproductive fitness and vectorial capacity of the malaria vector Anopheles gambiae (Diptera: (ulicidae). J Med Entomol. 2001;38:22-8.

41. Gimnig JE, Ombok M, Otieno S, Kaufman MG, Vulule JM, Walker ED. Density-dependent development of Anopheles gambiae (Diptera: Culicidae) larvae in artificial habitats. J Med Entomol. 2002;39:162-72.

42. Ferguson HM, Dornhaus A, Beeche A, Borgemeister C, Gottlieb M, Mulla MS, et al. Ecology: a prerequisite for malaria elimination and eradication. PLoS Med. 2010;7:e1000303.

43. Muriu SM, Coulson T, Mbogo CM. Godfray HCJ. Larval density dependence in Anopheles gambiae s.S., the major African vector of malaria. J Anim Ecol. 2013:82:166-74.

44. Thomson MC, Connor SJ, Quinones ML, Jawara M, Todd J, Greenwood BM. Movement of Anopheles gambiae s.l. malaria vectors between villages in The Gambia. Med Vet Entomol. 1995;9:413-9.
45. Costantini C, Li S-G, Torre AD, Sagnon NF, Coluzzi M, Taylor CE. Density, survival and dispersal of Anopheles gambiae complex mosquitoes in a West African Sudan savanna village. Med Vet Entomol. 1996;10:203-19.

46. Taylor C, Touré YT, Carnahan J, Norris DE, Dolo G, Traoré SF, et al. Gene flow among populations of the malaria vector, Anopheles gambiae, in Mali. West Africa. Genetics. 2001;157:743-50.

47. Boelee $E$, Cecchi $P$, Koné $A$. Health impacts of small reservoirs in Burkina Faso. Sri Lanka: International Water Management Institute; 2009. p. 40.

48. Sattler MA, Mtasiwa D, Kiama M, Premji Z, Tanner M, Killeen GF, et al. Habitat characterization and spatial distribution of Anopheles sp. mosquito larvae in Dar es Salaam (Tanzania) during an extended dry period. Malar J. 2005;4:4.

49. Nmor JC, Sunahara T, Goto K, Futami K, Sonye G, Akweywa P, et al. Topographic models for predicting malaria vector breeding habitats: potential tools for vector control managers. Parasit Vectors. 2013;6:14.

50. Fillinger U, Sonye G, Killeen GF, Knols BGJ, Becker N. The practical importance of permanent and semipermanent habitats for controlling aquatic stages of Anopheles gambiae sensu lato mosquitoes: operational observations from a rural town in western Kenya. Trop Med Int Health. 2004:9:1274-89.

51. Tirados I, Costantini C, Gibson G, Torr SJ. Blood-feeding behaviour of the malarial mosquito Anopheles arabiensis: implications for vector control. Med Vet Entomol. 2006;20:425-37.

52. Paaijmans KP, Wandago MO, Githeko AK, Takken W. Unexpected high losses of Anopheles gambiae larvae due to rainfall. PLOS ONE. 2007;2:e1146.

53. Martin PH, Lefebvre MG. Malaria and climate: sensitivity of malaria potential transmission to climate. Ambio (Sweden). 1997;24:200-2.

\section{Submit your next manuscript to BioMed Central and we will help you at every step:}

- We accept pre-submission inquiries

- Our selector tool helps you to find the most relevant journal

- We provide round the clock customer support

- Convenient online submission

- Thorough peer review

- Inclusion in PubMed and all major indexing services

- Maximum visibility for your research

Submit your manuscript at www.biomedcentral.com/submit
O Biomed Central 